\title{
Hydrothermal pretreatment of several lignocellulosic mixtures containing wheat straw and two hardwood residues available in Southern Europe
}

\author{
Talita Silva-Fernandes ${ }^{\mathrm{a}, \mathrm{b}}$, Luís Chorão Duarte ${ }^{\mathrm{a}}$, Florbela Carvalheiro ${ }^{\mathrm{a}}$, Maria Conceição Loureiro-Dias ${ }^{\mathrm{b}}$, \\ César Fonseca ${ }^{\mathrm{a}, *}$, Francisco Gírio ${ }^{\mathrm{a}}$ \\ a Laboratório Nacional de Energia e Geologia, I.P. (LNEG), Unidade de Bioenergia, Estrada do Paço do Lumiar 22, 1649-038 Lisboa, Portugal \\ ${ }^{\mathrm{b}}$ Instituto Superior de Agronomia (ISA), Universidade de Lisboa, Linking Landscape, Environment, Agriculture and Food (LEAF), Tapada da Ajuda, 1349-017 Lisboa, Portugal
}

\section{H I G H L I G H T S}

- Autohydrolysis was an efficient pretreatment for mixtures of lignocellulosic materials.

- Autohydrolysis profile is similar for different feedstock mixtures.

- Sugar-based biorefineries can use mixtures of hardwoods and agricultural residues.

- Feedstock mixtures potentially mitigate biomass supply constrains in biorefineries.

\section{A R T I C L E I N F O}

\section{Article history:}

Received 30 October 2014

Received in revised form 13 January 2015

Accepted 14 January 2015

Available online 7 February 2015

\section{Keywords:}

Biomass pretreatment

Biorefinery

Feedstock mixtures

Lignocellulose

Sugar recovery

\begin{abstract}
A B S T R A C T
This work studied the processing of biomass mixtures containing three lignocellulosic materials largely available in Southern Europe, eucalyptus residues (ER), wheat straw (WS) and olive tree pruning (OP). The mixtures were chemically characterized, and their pretreatment, by autohydrolysis, evaluated within a severity factor $\left(\log R_{0}\right)$ ranging from 1.73 up to 4.24 . A simple modeling strategy was used to optimize the autohydrolysis conditions based on the chemical characterization of the liquid fraction. The solid fraction was characterized to quantify the polysaccharide and lignin content. The pretreatment conditions for maximal saccharides recovery in the liquid fraction were at a severity range $\left(\log R_{0}\right)$ of 3.653.72 , independently of the mixture tested, which suggests that autohydrolysis can effectively process mixtures of lignocellulosic materials for further biochemical conversion processes.
\end{abstract}

(ㄷ) 2015 Elsevier Ltd. All rights reserved.

\section{Introduction}

Many lignocellulosic residues, by-products and energy crops have been tested in laboratory and demonstration scales to be used as feedstock for biorefineries (Fava et al., 2015; FitzPatrick et al., 2010; Larsen et al., 2008; Requejo et al., 2012; Saadatmand et al., 2012). However, the limited biomass availability and supply can be considered one of the major problems restraining the global biorefinery deployment (Balat, 2011). The seasonal nature and annual variability of biomass supply may impair the use of many feedstocks due to logistic/economic reasons (Yue et al., 2014), namely high transportation and storage costs. Moreover, the volatility of biomass cost and the dependence of specific suppliers are

\footnotetext{
* Corresponding author. Tel.: +351210924 717.

E-mail address: cesar.fonseca@Ineg.pt (C. Fonseca).
}

factors threatening the stability of a biorefinery (Gnansounou, 2010). The use of different biomass sources throughout the year may overcome these constrains, but different processing requirements may limit the success of a biorefinery.

An alternative that can minimize the problems related with biomass availability, seasonality, price volatility and storage, is the use of feedstock mixtures rather than a single raw material. Although some studies on mixtures are already available (Jensen et al., 2008; Martin et al., 2008; Thomsen and Hauggaard-Nielsen, 2008), the focus on technical evaluation of processing feedstock mixtures in the initial biomass pretreatment/fractionation stage is still scarce.

In this work, eucalyptus residues (ER), wheat straw (WS) and olive tree pruning (OP) were chosen as representative feedstock from Southern Europe, as they are widespread and significantly available in relatively concentrated regions. For instance, their 